\title{
LA FÁBULA POSMODERNA DE LA RED LIBRE Y DEMOCRÁTICA Y EL NUEVO PARADIGMA TECNO-POLÍTICO DE LA COMPUTACIÓN EN NUBE ${ }^{1}$
}

\section{THE POSTMODERN FAIRY TALE OF A FREE AND DEMOCRATIC NETWORK, AND THE NEW TECNO-Political PARAdigm Of CLOUd COMPUTING}

\author{
MARIA ANTONIETTA SALAMONE \\ salamomema@filos.ucm.es \\ Universidad Complutense de Madrid
}

RECIBIDO: $30 / 09 / 2018$

ACEPTADO: $15 / 11 / / 2018$

Resumen: El nuevo paradigma de la Computación en la Nube se identifica actualmente con la teoría política anarco-capitalista. Su objetivo es la explotación del territorio virtual a través del digital profiling para influir en las preferencias políticas de los ciudadanos-consumidores. El objetivo de la Democracia Liquida es la supresión de las viejas tecno-burocracias estatales mediante la promoción de nuevas tecno-burocracias digitales, cuyos mecanismos de funcionamientos son más oscuros que los precedentes. En nombre de la nueva libertad negativa automática y gratuita, la Ciudadanía 2.0 ha otorgado un mandato de gobierno privado a los dueños de la Computación en Nube para la defensa de sus derechos privados, en lugar de reivindicar un mayor espacio público para ejercer su razón práctica y defender la libertad republicana.

Palabras clave: Democracia Liquida, Posdemocracia, Posmodernismo, Digital Profiling, Marketing Político, Fakes News, Big Data, Algocracia, Libertad Negativa, Libertad Republicana, Neorealismo, Computación en Nube, Computación Cognitiva.

\begin{abstract}
The new paradigm of Cloud Computing currently identifies itself as anarcho-capitalist political theory. Its objective is to exploit the virtual territory through digital profiling in order to influence citizen-consumers' political preferences. The purpose of the so-called liquid democracy is the suppression of old state techno-bureaucracies, and the promotion of new digital technobureaucracies, whose operating mechanisms are even darker than the previous ones. In the name of a brand new free of charge, automatic, and negative freedom, instead of claiming a larger public space for exercising its practical reason and defend republican freedom, Citizenship 2.0 has granted a mandate of private government to the owners of Cloud Computing to protect their private rights.

Keywords: Liquid Democracy, Post -Democracy, Postmodernism, Digital Profiling, Political Marketing, Fakes News, Big Data, Algocracy, Negative Freedom, Republican Freedom, Neorealism, Cloud Computing, Cognitive Computing.
\end{abstract}

\footnotetext{
${ }^{1}$ Este artículo se inscribe en el proyecto de investigación Ciencia, Tecnología y Sociedad: Problemas políticos y éticos de la computación en nube como nuevo paradigma sociotécnico coordinado por Javier Bustamante Donas, financiado por el Ministerio de Economía y Competitividad (MINECO) en el ámbito del Programa Estatal de Investigación, Desarrollo e Innovación (I+D+i) orientada a los Retos de la Sociedad en el Marco del Plan Estatal de Investigación Científica y Técnica y de Innovación 2013-2016.
} 


\section{Premisa: el dilema ético del digital profiling}

La Computación en Nube $(\mathrm{CN})$ representa una etapa revolucionaria en el desarrollo de las ciencias computacionales y las telecomunicaciones. Es un nuevo paradigma tecno-político que tiene notables ventajas para los ciudadanos, pero presenta serios dilemas éticos y políticos que no pueden ser obviados. Según el Instituto Nacional de Estándares y Tecnología de Estados Unidos $(\mathrm{NIST})^{2}$, la Computación en Nube es «un modelo que posibilita un acceso de Red ubicuo, conveniente y bajo pedido, a una serie de recursos informáticos configurables y compartidos (redes, servidores, almacenamiento, aplicaciones y servicios) que pueden ser rápidamente utilizados y liberados con un mínimo esfuerzo y una mínima interacción con el proveedor del servicio. Este modelo en nube promueve la disponibilidad y está compuesto por cinco características específicas tres modelos de servicio y cuatro modelos de implantación». Estas características esenciales son las siguientes: 1) servicios bajo petición automática del usuario sin que sea necesaria ninguna interacción personal con el proveedor; 2) acceso a la Red desde cualquier dispositivo, ya sean potentes o no, incluidos teléfonos móviles, tabletas, etc.; 3) recursos compartidos (almacenamiento, memoria, procesamiento, anchura de banda, máquinas virtuales, etc.) disponibles para múltiples usuarios al mismo tiempo; 4) elasticidad y rapidez que permiten una percepción de disponibilidad ilimitada de recursos por parte de cada usuario, gracias a la escalabilidad de los sistemas en nube; 5) sistema de medición del servicio, que permite conocer a cada momento el uso de recursos por parte del sistema y de cada usuario para su optimización.

Al principio del siglo XXI los usuarios se esforzaban para comprender cómo gestionar su propio sistema local de archivos, y se perdían entre carpetas y ficheros; hoy, sin embargo, el nuevo espacio web del Cloud Computing se ha tragado todos estos objetos y los usuarios ignoran dónde sus contenidos online están dispersos en la Red. ¿Quién sabe dónde se encuentran nuestros emails? Los dispositivos hardware se hacen cada vez menos autónomos y sirven hoy en día casi exclusivamente para disfrutar de los servicios disponibles en la Red. Ya no

\footnotetext{
${ }^{2}$ El NIST es una Agencia federal del Departamento de Comercio de los Estados Unidos. Dentro del NIST, el Computer Security Resource Center (CSRC) y su Information Technology Laboratory se encargan de los estándares de las Tecnologías de la Información, y en concreto, de cloud computing. La definición de cloud computing está disponible en: <http://csrc.nist.gov/publications/drafts/800145/Draft-SP-800-145_cloud-definition.pdf >. En su última publicación de especificaciones de la nube de mayo de 2012, Cloud Computing Sypnosis and Recommendations, ya considera a cloud como una plataforma establecida y necesaria para las organizaciones.
} 
poseemos nada, todo es compartido con las grandes multinacionales de la Information Technology que nos brindan nuevos productos sin que tengamos que pagar un euro en muchos casos. En definitiva, para el usuario la informática se desvanece en la insoportable ligereza de las ciencias computacionales cuya utilidad, sin embargo, queda muy limitada en sociedades sin acceso universal a la Red y, por eso, se convierte en muchos casos en una poderosa causa de brecha tecnológica. Por ello es necesario aplicar el análisis de Winner ${ }^{3}$ sobre las tecnologías inherentemente políticas, o tecno-políticas, a las que define como aquellas que requieren un conjunto de requisitos sociales como condiciones necesarias de operatividad. En este sentido, podemos analizar el impacto de la Computación en Nube como constitución política de facto, y las prevenciones que debemos tener en un necesario debate social acerca de su implantación. ¿Estamos dispuestos a cambiar elementos tradicionales de nuestras formas de vidas y nuestros derechos ciudadanos para conseguir una mayor eficacia técnica? ¿Cuánta libertad personal estoy dispuesto a perder para que una empresa conozca mi perfil como consumidor? ¿Hasta qué punto es legítimo violar la integridad de las comunicaciones de carácter personal (emails, llamadas, etc.) para aumentar el nivel de protección frente a peligros de desestabilización del sistema? ¿Qué consecuencias políticas puede acarrear la personalización de la información a través de las burbujas de filtros? Todas estas preguntas nos advierten de que debemos prestar una atención especial a la forma en que la Computación en Nube altera la gramática del poder.

Uno de los problemas ético-políticos más cruciales con que nos enfrentamos se refiere, en efecto, a la vulnerabilidad de los agentes dominantes de la Computación en Nube frente al poder de los Estados centrales. Los designamos «agentes dominantes» o dueños digitales (proveedores de servicios y gestores de Big Data como Microsoft, Google, Amazon, Apple, Facebook, Skype, etc.), no solamente porque poseen los códigos del software que utilizamos, las informaciones que les regalamos, la potencia del cálculo y la mano de obra especializada para mantenerlo todo en movimiento, sino también porque han plasmado una mentalidad nueva promoviendo una Paideia Digital; es decir, una nueva pedagogía 2.0 que se caracteriza por impulsar una experiencia computacional orgánica y holística en la cual los usuarios se perciben a sí mismo, ontológica y psicológicamente, como partes integrantes del todo de la Red, libres de navegar en un gran Mare Nostrum. Por estados centrales o dueños analógicos entendemos, en cambio, aquellas naciones que tienen la capacidad de

\footnotetext{
${ }^{3}$ Winner, L. (2008) “¿Tienen política los artefactos?”, en Winner, L., La ballena y el reactor, Gedisa, Barcelona, pp. 37-54.
} 
tomar decisiones sobre las políticas tecnológicas que afectan a ámbitos extraterritoriales. En nombre de la lucha contra el terrorismo, la seguridad nacional, la defensa de los valores liberales, del libre comercio, etc., estas naciones ejercitan una presión cada vez mayor sobre las empresas tecnológicas para poder jugar un papel instrumental en estas políticas. De acuerdo con Bustamante, la extensión subrepticia de la información (function creep) y la vulnerabilidad de los agentes dominantes de la Computación en Nube frente al poder de estos gobiernos representan el problema ético-político más crucial con el que nos enfrentamos: «El problema esencial no se sitúa, pues, en el terreno de los hechos, sino en el de los derechos: se presenta esta disminución de control sobre la información de carácter personal como una consecuencia colateral intrínseca e inevitablemente unida a los beneficios esperables por el usuario: ¿por qué se queja de que le miremos el correo, si de esa forma le ayudamos a gestionar mejor sus citas y sus compras? Lo que está en juego es la propia redefinición de lo que entendemos como derechos personales en relación con los derechos que competen a los estados para promover el bien común y defender a la sociedad de sus enemigos. Para decidir qué tipo de sociedad queremos, debemos conocer las consecuencias políticas y éticas de las decisiones técnicas, ya que las tecnologías actúan como leyes: una vez extendidas, tienden a permanecer hasta que son sustituidas por otras, igual que las leyes son aceptadas inercialmente desde su promulgación hasta que son derogadas. Las tecnologías, igual que las leyes, son formas de vida: regulan la manera de entender el trabajo, el ocio, la participación política, y casi cualquier aspecto de la vida social que podamos imaginar». ${ }^{4}$

Y aquí aparece el gran problema técnico-político señalado: el llamado digital profiling; es decir el conjunto de procesos de construcción y aplicación de los perfiles generados por las tecnologías computacionales gracias al cual, a través del uso de algoritmos, se extrapola una serie de correlaciones para una gran cantidad de datos; de manera que datos de carácter personal, que han sido recogidos con un propósito concreto, se mezclan y combinan junto a otros para fines ajenos a la motivación originaria: desde componer un perfil de consumidor para ofrecer publicidad adecuada a sus patrones de consumo o efectuar marketing político, hasta emprender actividades de seguridad nacional en las que se clasifica a la población según su nivel de activismo social. Es verdad que el digital profiling no se aplica solamente a los individuos y es muy útil sobre todo para segmentar grupos de personas (análisis de clusters). Ahora bien, quien

\footnotetext{
${ }^{4}$ Bustamante, J. (2013), "Ética en la nube: dilemas éticos y políticos en el modelo de Computación en Nube (Ethics on the cloud: ethical and political dilemmas in the model of Cloud computing)", en Argumentos de Razón Técnica, nº16, 2013, pp. 37-54.
} 
considere que la seguridad esté por encima del derecho a la intimidad no tendrá ningún problema en aceptar la legitimidad de cierto grado de invasión en la privacidad personal. El problema es que los valores políticos aquí considerados (seguridad, control de la información de carácter personal, búsqueda de lucro, lucha contra el crimen, defensa de la libertad y la democracia, defensa de los derechos individuales a la vida y a la dignidad) no son valores absolutos. Es más, ninguno de ellos representa un bien exclusivo en una sociedad liberal. Mejor que una visión jerárquica o piramidal de estos valores políticos (del tipo: la libertad es más importante de que la justicia social, o la seguridad nacional es más importante que la libertad de expresión), los dilemas éticos en la sociedad tecnológica se presentan, según Queraltó ${ }^{5}$, como un sistema reticular, o como un sistema de pesos y contrapesos.

El propósito de este artículo es analizar la forma social y política de actuar del «ciudadano de la Red» (netizen, de net + citizen) que se percibe a sí mismo como parte integrante de la Computación en Nube en la cual fluye y goza libremente con la sensación de "participar democráticamente" en la vida sociopolítica global, gracias sobre todo al uso de las redes sociales. En efecto, los movimientos de indignación populares y los partidos líquidos, nacidos en contacto constante con las tecnologías computacionales, son movimientos de masas que se han dado cuenta de que pueden dar voz a sus ideas, puesto que la libertad de expresión es uno de los eslóganes con los cuales promueven los flujos constantes de información necesarios para la expansión de la Red. La antigua virtud de la panresía (del griego pan, «todo», y rhema, «lo dicho») se convierte así en un imperativo categórico que prescribe exhibir las propias razones viscerales online, lo cual amplifica el sentido de igualdad e identidad entre los ciudadanos de la Red que están muy a gusto poniéndose la máscara del conspirador inglés Guy Fawkes en lugar de cultivar sus identidades y personalidades multidimensionales. El objeto principal de esta mayoría indignada es la supresión de las tecno-burocracias estatales, percibidas como establishments corruptos, clientelares, fuertes con los débiles (los ciudadanos) y débiles con los fuertes (Unión Europea, Banco Central Europeo, Fondo Monetario Internacional, etc.). Lo paradójico es que estos movimientos quieren eliminar estas viejas tecno-burocracias estatales apoyándose en las nuevas tecnoburocracias digitales, cuyos mecanismos de funcionamientos son más oscuros que los precedentes. La misma Red se convierte así en una especie de metanarración ideológica y omnicomprensiva porque pretende resolver, pero lo hace

\footnotetext{
${ }^{5}$ Queraltó, R. (2008), La Estrategia de Ulises o Ética para una Sociedad Tecnológica, MadridSevilla: CICTES-Doss. Ed.
} 
sólo aparentemente, los clásicos problemas de la democracia, es decir la honestidad de los ciudadanos/gobernantes y la real participación de los ciudadanos en la vida democrática.

Esta forma de narración posmoderna es una forma de capitalismo biopolítico profundamente destinado a la recogida, almacenamiento, agregación y trasformación de aquella serie de metadatos y datos que configuran los Big Data. Sin embargo, la democracia no es un código, ni mucho menos un software, y no se realiza a través de una nueva cesión tecnocrática. En lugar de tomar el Palacio de Invierno de la maquina estatal a través de los mecanismos de la democracia representativa, los ciudadanos de la Red deberían empezar a ocupar también los territorios fronterizos y marginales a través de buenas prácticas de micropolíticas diarias, porque solamente en una dimensión local es posible promover una nueva cultura tecnológica y política basada en la confianza. La areté del nuevo espacio web de la Computación en Nube no se identifica para nosotros con la teoría y la práctica política anarco-capitalista que, tras haber colonizado el territorio real a través de la globalización económica, se dedica ahora a la explotación del territorio virtual a través de una nueva forma de colonialismo que toma el nombre de digital profiling con el objeto de establecer las preferencias también políticas de los ciudadanos-consumidores a través del marketing político. El riesgo es que la Computación en Nube, que por otra parte representa una oportunidad única para los ciudadanos de la $\operatorname{Red}^{6}$ (las plataformas digitales y las redes sociales ya se ha integrado a la vida diaria y es imposible extirparlas o excluirlas de sus efectos políticos), se convierta finalmente en el Caballo de Troya posmoderno, al esconder el engaño más viejo del mundo: el de hacer dinero aprovechando de la superficialidad e ingenuidad digital de los usuarios. Es necesario ser conscientes de los costes para la democracia de esa tendencia tecnocrática.

\section{La democracia líquida anti-establishment}

El término democracia ha tenido diferentes significados a lo largo de la historia. En todo caso fue acuñado en Grecia entorno al siglo VI a.C. y hacía referencia a un sistema de gobierno en el cual los ciudadanos de una comunidad deliberaban en la asamblea popular a través de un voto que tenía igual peso. En la Atenas

\footnotetext{
${ }^{6}$ Queraltó, R. (2000), El caballo de Troya al revés: diseño de una estrategia ética en la sociedad tecnológica, [en De Mora, Ibarra, Pérez Sedeño y Sánchez Balmaseda, coord.: Actas del III Congreso de la Sociedad de Lógica, Metodología y Filosofía de la Ciencia en España, San Sebastián, Universidad del País Vasco, 2000] págs. 301-308.
} 
democrática, además, ninguna magistratura política era vitalicia sino más bien de corta duración (un año como media), y es por eso que el $70 \%$ de los ciudadanos atenienses con más de treinta años terminaba siendo designado por sorteo buleutas. Ahora bien, podemos escribir la historia de la palabra democracia empezando por la antigua Grecia, o tal vez, podemos escribir una historia de aquellos procedimientos igualitarios para la creación del consenso que fueron definidos como democráticos en Atenas. Normalmente, damos por descontado que los dos significados se refieren a lo mismo porque el sentido común nos indica que la democracia, así como la filosofía, fueron inventadas en la antigua Grecia. Sin embargo, comunidades igualitarias han existido siempre a lo largo de la historia humana, y todas utilizaban procedimientos específicos para deliberar sobre los asuntos más relevantes de la ciudad. Sen, ${ }^{7}$ por ejemplo, sostiene que la tradición intelectual occidental en su conjunto se resiste a reconocer como democracia cualquier cosa que así podría definirse en otras civilizaciones, como la india, la china o la mesopotámica. La razón principal radica en que en aquellos procedimientos asamblearios muy raramente se hacía uso del voto, y casi invariablemente los individuos deliberaban a través de la discusión pública y la búsqueda del consenso. Un procedimiento consensual no tiene nada a que ver con un debate parlamentario y no se parece nada a una votación. Se trata, más bien, de un proceso de mediación y de síntesis, cuyo fin es el de tomar unas decisiones que nadie puede rechazar razonablemente, lo cual implica el disenso. Sen sintetiza esta cuestión afirmando que podemos distinguir dos visiones de la democracia: por un lado tenemos una «concepción institucional» (formal) de la democracia vista ante todo como «sistema electoral», como elecciones y votos; según esta visión, las elecciones políticas abiertas, libres y equitativas constituyen la esencia de la democracia. Por el otro lado tenemos una «concepción real» (sustancial) de la democracia vista como «el gobierno por discusión» o el ejercicio del razonamiento público. Según esta visión, la esencia de la democracia deliberativa radica en la misma idea de deliberación: vivimos en una democracia cuando los ciudadanos deliberamos, intercambiamos opiniones y debatimos nuestras razones a favor de cuestiones políticas públicas. De tal manera que según esta visión las cuestiones centrales para una comprensión amplia de la democracia son la participación política, el dialogo y la interacción pública.

Es necesario, por tanto, preguntarse qué espacio tenemos hoy en día para la realización de una democracia sustancial en la Computación en Nube a través del

\footnotetext{
${ }^{7}$ Sen, A. (2010), La idea de la justicia, Madrid: Taurus.
} 
uso de las plataformas digitales dedicadas. Actualmente existen dos tendencias muy en boga:

1. El Clicktivism o el Clicktivismo es un neologismo que denomina al llamado activismo de sillón y click. Se trata de una forma de realizar activismo virtual sin abandonar las actividades habituales, y por lo general interactuando en las redes sociales. Detrás de las plataformas digitales dedicadas -las dos más populares del mundo son Avaaz y Change.org - está la idea que los grandes problemas sociales no se atacan desde grandes organizaciones expertas en el tema, sino que cada persona puede contribuir a solucionarlos desde su lugar generando un sumatorio de microcambios. Se trata fundamentalmente de apoyar y promover una causa política en los medios sociales, pero el clicktivismo puede incluir toda una gama de actividades como: organizar protestas, facilitar el boicot, firmar peticiones, hacer parodia y sátira en línea, eludir bloqueos informativos, mantener a la gente informada, etc.

2. La Liquid Democracy o Democracia Liquida es "la suma de la democracia directa y participativa que se desarrolla a través de nuevas tecnologías que logran superar el límite representativo". 8 Con esta concepción, la Democracia Líquida encuentra sus dos pilares en la delegación del voto soberano y en la construcción de un Parlamento Virtual. No en vano a la Democracia Líquida también se le denomina democracia delegativa. En efecto, la Democracia Liquida es un modelo de organización política por el cual los ciudadanos no delegan su soberanía en representantes políticos fiduciarios durante periodos fijos (legislaturas políticas), sino que la ejercen de varias formas, siempre haciéndose presentes en las instituciones representativas a través del voto electrónico por cualquiera de las plataformas digitales dedicadas o las redes sociales cibernéticas. Las plataformas digitales permiten la inclusión de la participación ciudadana en las instituciones, principalmente a través del correo, el voto electrónico y los wikis (en especial Wikileaks, la Wikipedia y la Wikilegislación, no sólo en el sentido de quién las consulta, sino también de quiénes las construyen). Mientras que las redes sociales (chats, foros, blogs, el Facebook, el Twitter, las cuentas de Yои Tube de colaboración abierta, las cuentas de Mp3, y el

\footnotetext{
${ }^{8}$ Vestri, G. (2015), “¿La Democracia Líquida como alternativa a la política clásica? Un estudio contextual”, Estudios de Deusto, Vol.63, No. 1, pág. 410.
} 
$P 2 P$, etc.) posibilitan en mayor medida la interacción deliberativa y la comunicación multilateral para construir el ágora digital. ${ }^{9}$

La delegación soberana no responde a una representación política fiduciaria, es decir, no se basa en la elección de representantes políticos cuyas decisiones y acciones no son vinculantes ni solidarias con las preferencias de sus representados. El modelo líquido está basado, en efecto, en la potestad de sustituir la representación política por la delegación; es decir, un ciudadano tiene la alternativa de participar directamente o depositar en otro su soberanía para que su depositario (denominado representante o apoderado proxy) actúe en el sentido o la intención que le es encomendada de manera imperativa. O si fuera el caso, para que el proxy lo haga de conformidad a su parecer, - si se encuentra autorizado para ello -, con el compromiso de que la delegación de la soberanía puede serle revocada en cualquier momento para que regrese al ciudadano originario. El apoderado proxy también puede delegarse en otro proxy si lo considera más adecuado o competente y está autorizado para ello por el ciudadano originario. La soberanía, en el modelo líquido, se ejerce no sólo para elegir a un apoderado proxy ad hoc al caso requerido en la agenda política, sino también para deliberar sobre los asuntos públicos, para participar en la elaboración de las políticas públicas, decidir y ejecutar planes y programas de acción. $^{10}$ Las ventajas que la representación delegada ofrece sobre la representación fiduciaria -afirman sus partidarios- son precisamente las que provocan la superioridad del modelo democrático participativo en su versión líquida sobre el modelo representativo. Dicha superioridad, en pocas palabras, implica más demos en el kratós, es decir, involucra a más y mejores ciudadanos y lo logra en términos de mayor igualdad soberana.

Ahora bien, la cuestión crucial de la Democracia Líquida es que la deliberación política es asistida por software de participación de masas: se trata de una nueva forma para la toma de decisiones colectivas a través de la delegación tecnocrática a los filtros algorítmicos capaces de extrapolar la opinión de la mayoría, como el algoritmo PageRank utilizado por Google, el software LiquidFeedback utilizado por el Partido Pirata Internacional ${ }^{11}$ o el

\footnotetext{
${ }^{9}$ Aguirre Sala, J.F., (2017), La democracia líquida. Los nuevos modelos políticos en la era digital, Barcelona: Editorial UOC.

${ }^{10}$ The Liquid Democracy Journal compila una serie de artículos sobre la democracia liquida. Disponible en: http://www.liquid-democracy-journal.org/

${ }^{11}$ El Partido Pirata Internacional, fundado en 2006 en Suecia y Alemania, en el año 2009 alcanzó dos escaños en el Parlamento de la Unión Europea; en 2012, dos senadurías nacionales en la República Checa e Islandia; en 2014 alcanzó en Alemania 251 escaños locales y uno en el Parlamento de la Unión Europea; en octubre de 2016 se convirtió en la tercera fuerza política de Islandia,
} 
software Rousseau utilizado por el partido líquido italiano denominado Movimiento Cinco Estrellas (M5S). ${ }^{12}$ En España, entre los partidos líquidos que utilizan tecnologías parecidas pueden enumerarse los proyectos no consolidados de la «Red Ciudadana Partido X: Democracia y Punto» y del «Partido de Internet», así como el intento de organización interna y responsabilidad militante que declaran los partidos «Podemos» y «Barcelona en Comú (BComú)». El caso del citado M5S italiano, sin embargo, es el más representativo y merece una atención particular al ser el primero partido político en nacer de un "blog", además de ser el más votado en las elecciones italianas de 2018 (32,6\%), y está a punto de convertirse en el primer partido digital al mundo en llegar al poder ejecutivo. Sus dirigentes pentaestrellados precisan que el Movimiento no es un partido político - ni pretenden que lo sea en el futuro -, sino una asociación libre de ciudadanos que no tienen ideologías de izquierda o derecha, sino ideas políticas. Más aún, dicen que el movimiento es biodegradable y que se disolverá cuando logremos hacer un referéndum semanal desde nuestras casas. Desde el punto de vista de la Computación en Nube, el Movimiento tiene un único dueño digital, la empresa privada Casaleggio Associati, que controla de facto la Plataforma Digital del Movimiento. Pero: ¿qué es lo que puede hacer el elector pentaestrellado con el sistema operativo Rousseau? Pues bien, además de las funciones principales de participar en la redacción de los proyectos de leyes regionales y nacionales, y la de votar para la formación de las listas electorales del Movimiento (en el supuesto democrático de que cada ciudadano tiene el mismo derecho para concurrir a la formación de la ley y al nombramiento de sus mandatarios), estas son las demás funciones de la plataforma:

- Mediante la función Lex Europa se puede participar en la discusión sobre los proyectos de leyes europeas.

- Mediante la función Lex Parlamento se puede participar en la discusión sobre el primer borrador de los proyectos de leyes presentados por los portavoces del Movimiento elegidos en la Cámara de los Diputados y en el Senado.

- Mediante la función Fund raising se puede donar y recoger fondos para la financiación de la plataforma digital, de las campañas electorales y de todas las demás iniciativas del Movimiento.

- Mediante la función Escudo de la Red ser puede recibir asesoramiento legal gratuito en caso de demandas presentadas contra el Movimiento.

\footnotetext{
${ }^{12}$ La Plataforma digital Rousseau: https://rousseau.movimento5stelle.it/rousseau.php.
} 
- Mediante la función E-learning se puede participar en cursos didácticos online para aprender a ser "portavoz del Movimiento", "concejal de ayuntamiento", etc.

- Mediante la función Sharing se puede compartir los proyectos de leyes promovidos por el Movimiento en las Regiones y los Ayuntamientos italianos.

- Mediante la función Call to action se puede "crear una iniciativa personal" o dar vida a una acción de ciudadanía activa de movilización, colaboración, información, señalación, interacción, argumentación, con los grupos territoriales del Movimiento ( meetup).

- Mediante la función Activism se puede localizar y participar en los eventos oficiales organizados por el Movimiento en todo el territorio nacional, además de recibir información actualizada sobre las ágoras temáticas, las asambleas públicas, los congresos y seminarios, organizados por los portavoces del Movimiento en su propia ciudad.

Sin querer disminuir el valor político de todos estos movimientos sociales, el problema de la Democracia Liquida es que la deliberación asistida por software de participación de masas tiene poco que ver con la búsqueda del consenso propia de la democracia participativa. Además, esta idea del link como expresión de un voto positivo tiene un origen cultural. Se trata de la traducción matemática del mecanismo de citación científica: cuanto más valorado positivamente sea un artículo por los demás científicos, más importante y meritorio será considerado. Los fundadores de Google han aplicado este enfoque en su propio campo de investigación llegando a desarrollar la teoría según la cual el número de links que conduce a una página web es una manera objetiva de evaluar el valor y la cualidad de la misma. La cuantidad se transforma por encanto algorítmico en cualidad. Google habla expresamente de «voto» porque en su visión cada link equivale a un voto, de manera que un sitio web fuertemente votado (linkeado) se encontrará en una posición de ventaja en el ranking con respecto a otro menos conocido. En la República de los algoritmos de Google el PageRank se presenta, pues, como una especie de citation index vulgarizado, vehiculando una idea de democracia directa cuanto menos demagógica. En casi todos los análisis, en efecto, se oculta el hecho de que las redes sociales y las plataformas digítales han sido fundadas con el objeto de la ganancia, y no con la idea de crear un contesto democrático global de debate intercultural para desafiar los problemas a los que nos enfrentaremos en las próximas décadas - escasez energética, terrorismo, cambio climático y pandemias - y que solo podremos solucionar juntos. El 
ciudadano de la Red, por el contrario, se siente investido de la gran oportunidad de refundar la democracia en sentido global. Ahora bien, de acuerdo con Bobbio, la única democracia posible es un sistema integral entre la democracia participativa y la democracia representativa: «un sistema de democracia integral puede abarcar a las dos, a cada una de acuerdo con las diversas situaciones y las diferentes necesidades, porque son, en cuanto adaptables a diversas situaciones y a diferentes necesidades, perfectamente compatibles entre ellas». ${ }^{13}$ La síntesis busca conciliar las insuficiencias representativas con el arquetipo ideal de la democracia directa clásica. Castoriadis ${ }^{14}$ recordaba el argumento principal en contra de la democracia participativa en la sociedad contemporánea: la dimensión de la población. El régimen representativo como lo conocemos era desconocido en la Antigüedad: apareció en Occidente a partir del siglo XI en las ciudades italianas que aspiraban al autogobierno. Estas ciudades contaban con no más de seis mil ciudadanos, es decir un orden de magnitud inferior respecto a los treinta o cuarenta mil ciudadanos activos en la Atenas del periodo clásico y, a diferencia de entonces, no elegían magistrados sino representantes.

La idea de representación es una idea moderna; no obstante, su origen no tiene nada a que ver con la dimensión de la población. La democracia participativa se podría tranquilamente establecer en unidades que congreguen cuarenta mil ciudadanos activos, pero deberían ser personas que se conozcan de visu y compartan un medio ambiente, unos recursos, unos barrios urbanos, pequeñas ciudades, o federaciones de pequeñas comunidades. En lugar de eso, los partidos líquidos 2.0, es decir, los movimientos digitales, reticulares e interconectados (los International Pirate parties, Anonymous, WikiLeaks, los grupos que digitalizan los movimientos sociales como Occupy Wall Street o el Movimiento 15-M, también llamado Movimiento de los indignados, los partidarios de la consulta y deliberación online, los entusiastas de la $e$ Democracy) que se presentan como las nuevas formas de agregación política que quieren barrer el viejo mundo de la política 1.0, hablan prevalentemente de «alcanzar la masa crítica» y, por tanto, las plataformas de e-Democracy no se alejan del modelo hegemónico de las redes sociales privadas que promueven una cultura neo-colonialista. Estos movimientos, en efecto, tienen una clara vocación de masa y populista: reivindican la Leaderless resistance (resistencia sin leader), es decir la ausencia de jefes, exaltan los iconos o los ídolos carismáticos (como por ejemplo, Beppe Grillo en el caso del Movimiento Cinco Estrellas), expresan

\footnotetext{
${ }^{13}$ Bobbio, N. (2005), El futuro de la democracia, México: Fondo de Cultura Económica, Págs. 6061.

${ }^{14}$ Castoriadis, C. (2007), Democracia y Relativismo: debate con el MAUSS (Mouvement AntiUtilitariste dans les Sciences Sociales), Madrid: Trotta.
} 
un virulento rechazo hacia las oligarquías políticas, económicas e institucionales dominantes consideradas corruptas e injustas, y comparten el idolum según el cual la Red es libera y democrática. Se dice, en efecto, que el valor central que congrega a todos estos movimientos es la libertad. Con eso se entiende, principalmente que son movimientos políticos prevalentemente euroescépticos, ya que comparten los mismos enemigos a nivel internacional - el Banco Mundial, el Fondo Monetario Internacional, el Banco Central Europeo y la Unión Europea -; mientras que, a nivel nacional, son movimientos antiestablishment ya que están en contra de la ley de hierro de la oligarquía de los partidos políticos tradicionales ${ }^{15}$ (considerados analógicos) y de sus relativos mecanismos de votos. Ahora bien, ser capaces de votar directamente o enviar propios representantes en los diferentes Parlamentos locales, nacionales y europeos (concepción formal de la democracia) no implica haber dado un paso adelante decisivo hacia la democracia participativa (concepción real de la democracia) y, sobre todo, no supone haber planteado una solución alternativa a la deliberación política.

\section{Echando una mirada hacia la tradición republicana}

El verdadero argumento a favor de la democracia representativa lo pronunció Constant ${ }^{16}$ en su discurso en el Ateneo de Paris en 1819, que representa un manifiesto programático de la concepción liberal de la libertad del siglo XIX y un acto de acusación contra la democracia directa de Rousseau. En su conferencia titulada De la libertad de los antiguos en comparación con la de los modernos, Constant planteaba esa distinción como útil para justificar los logros de las revoluciones liberales de Inglaterra, Estados Unidos y Francia, en orden al disfrute de una libertad política, hasta ese momento desconocida, y que se materializaba además de en la proclamación y garantías de las libertades o

\footnotetext{
${ }^{15}$ La ley de hierro de la oligarquía es el instrumento que sostiene lo que en Italia se denomina partidocracia, y se basa en los siguientes hechos: los gobernantes no son verdaderos delegados de la soberanía de los ciudadanos, sino representantes desvinculados de sus representados. Dichos representantes son elegidos con métodos establecidos por ellos mismos. Las elecciones se hacen de una lista cerrada de candidatos, cuyo listado, a su vez, es exclusivo para grupos registrados por sí mismos como partidos políticos. Una vez instaurados como representantes, se amplían las reglas de su oligarquía: el clientelismo, el patrimonialismo y el corporativismo. Véase: Michels, R.: 1962 [1910]). Political Parties. A Sociological Study of the Oligarchical Tendencies of Modern Democracy, USA: Library of Congress. Transaction Publishers. New Jersey.

${ }^{16}$ Constant, B. (2002), Sobre la libertad de los antiguos en comparación con la de los modernos, Madrid: Tecnos.
} 
derechos individuales, en el establecimiento del gobierno propio del modelo liberal de Estado, es decir en el gobierno representativo y en la división de poderes políticos, cuyo fundamento es la soberanía popular. Lo que en definitiva planteó Constant es la distinción entre el ámbito de lo público y el ámbito de lo privado, entre democracia participativa y democracia representativa, precisando que hay dos tipos de libertades: la libertad política de los antiguos que se concreta estrictamente en el reparto del poder político-social entre los ciudadanos, y la libertad de los modernos que se concreta principalmente en los derechos individuales de la persona que deben ser garantizados por la ley: «El objetivo de los antiguos era el reparto del poder social entre todos los ciudadanos de una misma patria; a eso era a lo que llamaban libertad. El objetivo de los modernos es la seguridad en los disfrutes privados; y llaman libertad a las garantías concedidas por las instituciones a estos disfrutes».

Según Constant, y luego también Berlin, ${ }^{17}$ el modelo liberal de Estado de Derecho que se edificó durante la Ilustración promovió un aparato coercitivo que garantizó principalmente la libertad negativa: y en esto consistiría, en definitiva, la democracia representativa de corte liberal. Ahora bien, aunque en el uso político habitual de los términos liberalismo y democracia son equivalentes, Bobbio, ${ }^{18}$ apoyándose en las ideas expuestas por Constant, establece una distinción histórica entre ambas formas políticas afirmando que mientras el liberalismo sostiene que ser libre significa no estar sometido a interferencias (libertad negativa), la democracia defiende que ser libre significa, ante todo, poder decidir las normas que regulan la vida social (libertad positiva). O dicho de otra forma, el liberalismo encarna el principio de la libertad individual y la democracia encarna el principio de descentralización del poder político. Sin embargo, de acuerdo con Viroli y muchos otros autores, es con el redescubrimiento y la difusión de la tradición política republicana al comienzo de la época moderna, que el concepto de libertad recobra su significado originario al poner de manifiesto que ser libre quiere decir (en primer lugar) «no depender de la voluntad arbitraria de otros individuos». ${ }^{19}$ En efecto, para los escritores políticos humanistas y renacentistas, tanto católicos reformistas ${ }^{20}$

\footnotetext{
${ }^{17}$ Berlin, I. (2010), Dos conceptos de libertad, Madrid: Alianza Editorial.

${ }^{18}$ Bobbio, N. (1986), Liberalismo e Democrazia, Milano: Franco Angeli.

${ }^{19}$ Viroli, M. (1994), Dalla política alla ragion di Stato, Milano: Donzelli.

${ }^{20}$ Salamone, M.A. (2006), "La idea del contrato social en M. Salamone de Alberteschi. Sus vínculos con la Escuela de Salamanca y el Constitucionalismo inglés”, Madrid, Universidad Complutense. "La doctrina política del contractualismo en M. Salamone y la Escuela de Salamanca" en Ciencia e investigación en la sociedad actual, Salamanca: Editorial San Esteban, 2010; "De las primeras Cartas de derechos a la Declaración Universal de los Derechos Humanos" en Los derechos humanos en su origen. La República dominicana y Antón Montesinos, Salamanca: Editorial San Esteban, 2011.
} 
como protestantes, y con anterioridad a las grandes formulaciones políticas de la Ilustración de Locke y Rousseau, lo opuesto a la dependencia no es la libertad del estado de naturaleza, sino la dependencia de las leyes no arbitrarias válidas para todos. Retomando el significado de república de Cicerón, para quien «res publica» quiere decir «lo que pertenece al pueblo» (res publica res populi) entendiendo con esto una sociedad organizada cuyo fundamento es la observancia de la justicia y la comunidad de intereses,- por ejemplo Rousseau afirmará que "Llamo república, pues, a todo Estado regido por leyes, cualquiera que sea su forma de administración, ya que sólo entonces es el interés público el que gobierna, y la cosa pública se concreta en algo". ${ }^{21}$

La libertad republicana, en definitiva, se concibe como independencia de la voluntad arbitraria de otros individuos, pero no se concibe como independencia de la ley, ya que todos - gobernantes y gobernados - deben estar sometidos a ella. Por eso, quien ama la verdadera libertad del individuo no puede no ser liberal, pero no puede ser sólo liberal. Debe estar dispuesto asimismo a defender programas políticos cuyo fin sea reducir los poderes arbitrarios que impongan a muchos hombres y mujeres una vida en condiciones de dependencia. Tras las Segunda Guerra Mundial, en efecto, en las democracias europeas occidentales prevaleció, en los debates políticos, la postura de la izquierda socialdemócrata partidaria de un modelo de Estado social que entrañaría una radical trasformación con respeto al Estado liberal-democrático: en el nuevo modelo político constitucional republicano, el Estado pasa de ser un mero garante de los derechos y libertades individuales y civiles a transformarse en un prestatario de medidas y actuaciones socio-económicas que van desde el reconocimiento y garantías de los denominados derechos económicos, sociales y culturales hasta la prestación de medidas asistenciales o la aplicación de políticas fiscales redistributivas, por lo que el nuevo modelo de Estado social se manifiesta como intervencionista en las relaciones económicas y productivas, antes exclusivamente en mano de la burguesía capitalista. Esto supone una gran trasformación en el tratamiento jurídico-político de la igualdad y la libertad: por un lado ambos ámbitos se ven ampliados en el sentido de que se camina hacia una pretendidamente efectiva igualdad económica y social; por otra se amplían las libertades en la medida en que la igualdad se concreta en derechos que se extienden a todos los individuos sin excepción por motivo de sexo, raza religión o clase social.

Si el Estado liberal se caracterizó por su pretensión de conseguir la justicia legal o formal (igualdad aritmética) de los ciudadanos ante la ley y la protección

\footnotetext{
${ }^{21}$ Rousseau, J. (1979), El contrato social, en Escritos de combate, Madrid: Alfaguara, pág. 432.
} 
de sus libertades públicas, el Estado social republicano, al extender la protección de dichas libertades públicas a todos los ciudadanos (primero con la inclusión del sufragio femenino), se caracterizó por su pretensión de conseguir la justicia real o distributiva (igualdad geométrica o proporcional) entre los ciudadanos, a través de una redistribución de los derechos económicos y sociales con arreglo a los méritos, capacidades y necesidades de cada uno. Todo lo cual se vio reflejado, por ejemplo, en la Constitución democrática española de 1978: «Este principio general de justicia, expresado en estos dos modos (igualdad aritmética o formal y distributiva o real) se concreta tanto en el principio de igualdad formal ante la ley (art. 1,1 E) como en el principio de igualdad real (art. 9,2 CE). Un ejemplo de la primera es el derecho fundamental que aparece en el art. $14 \mathrm{CE}$ (que hace referencia a la igualdad puramente aritmética o legal), y de la segunda el derecho fundamental reconocido en el 23,2 $\mathrm{CE}$ (en el acceso a cargos públicos) que se refiere a la proporcional». ${ }^{22}$ Así que precisamente porque el fin de la democracia y del Estado de Derecho es la justicia o el bien común, y no el bien particular o individual de algunos arrogantes, ambiciosos y viciosos, es preciso que los liberales sepan y quieran salvaguardar no sólo la libertad negativa sino también la libertad republicana, y ese debería ser precisamente también el objetivo de una Red democrática, en lugar de estimular el voto compulsivo sobre cualquier argumento.

\section{El ataque de la contra-Ilustración a la razón práctica}

Ahora bien, en los últimos cincuenta años y de manera más evidente tras la ruptura del orden mundial establecido por la Guerra Fría (1989), una crisis sistémica parece afligir la democracia representativa (proceso de desdemocratización) y la misma idea de Estado de Derecho liberal-republicano (proceso des-estatización). Tres son los factores interconectados de esta crisis sistémica de la democracia, que afectan a las tres dimensiones (política, institucional y jurídica) en que se articula la democracia constitucional:

Dimensión política. El primer factor de crisis lo constituye la personalización y verticalización de la representación política, es decir la falta de representación política de los intereses de las minorías. En casi todos los estados democráticamente avanzados, hemos asistido a lo largo de estos últimos veinticinco años a un reforzamiento del poder ejecutivo, con la consiguiente pérdida de autoridad de los Parlamentos. La representación política, debido a la

\footnotetext{
${ }^{22}$ Gómez Adanero, M. (2013), Filosofía del Derecho, Madrid: UNED.
} 
difusión del modelo presidencialista o de sistemas electorales claramente mayoritarios (y no proporcionales) tiende cada vez más a identificarse con la personalidad del jefe del Estado o del gobierno. Así que la actual democracia representativa consistiría, más que en la representación de los diversos intereses sociales y de su discusión parlamentaria, en la selección por vía electoral de una mayoría de gobierno, y con ella del jefe de esta mayoría, quien sería por lo tanto la máxima expresión de la voluntad popular. Ha triunfado, pues, la democracia formal, vista como sistema electoral, en lugar de la democracia real vista como el gobierno por discusión. Las consecuencias de esta crisis política son graves: por un lado, el debilitamiento de los partidos políticos tradicionales como ámbitos e instrumentos de adhesión social, de formación colectiva de programas y opciones políticas, de representación de intereses y propuestas diferenciadas e incluso en conflicto. Por otro lado, una involución anti-representativa de la democracia representativa dado que, como nos enseñó Kelsen ${ }^{23}$, «un órgano monocrático no puede representar la voluntad de todo el pueblo, y ni tan siquiera de la mayoría». La respuesta a la crisis política de la democracia ha sido el ascenso en toda Europa de movimientos políticos líquidos y nacionalistas, y por ende anti-establishment y anti-europeístas, que han sustituido gradualmente a la izquierda socialdemócrata del siglo pasado, incapaz de defender los intereses de la clase media europea.

Dimensión institucional. El segundo factor de crisis consiste en la pérdida progresiva de separación entre los poderes políticos y los poderes económicos, entre Estado y mercado, entre democracia y capitalismo. Esta progresiva concentración de los poderes públicos y privados se inicia al postular la primacía del mercado sobre el Estado, lo cual provoca la subordinación de los poderes del gobierno a los grandes poderes e intereses económicos privados, y el establecimiento de una estrecha alianza entre los poderes políticos y los poderes mediáticos que gestionan los medios de comunicación de masas. No se trata de una simple subordinación de los intereses públicos a los intereses privados, sino de un fenómeno patológico que descompone las formas mismas de la representación política aniquilando así un presupuesto elemental de la democracia, que es la libertad de información y el pluralismo de los medios de comunicación. Ante la ausencia de límites y de equilibrios entre los poderes, conduce a dos modalidades convergentes de absolutismo: el absolutismo de la mayoría y el absolutismo del mercado; la omnipotencia de los poderes políticos mayoritarios y la ausencia de reglas y controles sobre los poderes económicos. El paradigma tecno-político de la Computación en Nube constituye una de las

\footnotetext{
${ }^{23}$ Kelsen, H. (2011), Teoría pura del derecho, Madrid: Trotta.
} 
respuestas más eficaces a la crisis institucional de la democracia - y de sus mainstream media tradicionales -, ya que hoy en día los ciudadanos de la red rechazan en su mayoría la televisión y la prensa escrita, informándose prevalentemente a través de internet y de las redes sociales, hasta el punto de plantearse -como hemos visto anteriormente - formas alternativas de democracia liquidas y digitales.

Dimensión jurídica. Llegamos así al tercer factor de crisis de la democracia representativa, es decir, la crisis de la legalidad, tanto constitucional como ordinaria, y con ella del paradigma del Estado de Derecho como sistema de límites y de restricciones impuestos a los poderes políticos de la mayoría y a los poderes económicos del mercado. La concentración, confusión y vocación absolutista de los poderes públicos y privados equivalen, de hecho, a una nueva y más actual versión de «los gobiernos de los hombres», en lugar del republicano «gobiernos de las leyes». Por consiguiente, no se debilitan únicamente las garantías institucionales de los derechos humanos fundamentales, tanto individuales como sociales, sino que se apunta directamente a la privatización progresiva de la esfera pública y de las funciones que a ella corresponden: en materia de educación, de seguros sociales, de asistencia sanitaria, y también en materias tradicionalmente reservadas a las competencias del Estado incluso en el viejo modelo liberal, como son la jurisdicción civil, la ejecución de las penas en la cárcel, las funciones del orden público y hasta las de defensa militar, que pueden confiarse a fuerzas mercenarias privadas. Queda así dinamitada en su totalidad la estructura del estado constitucional de derecho, entendido como instrumento para garantizar los derechos fundamentales, los cuales quedan degradados a derechos patrimoniales, mercantilizables y negociables, en claro contraste con su carácter universal y con su rango constitucional. Por consiguiente, queda dinamitada también nuestra libertad republicana, nuestra capacidad de decisión sobre los asuntos públicos y se vislumbra una rápida expansión de lo que hoy se llama «posdemocracia» ${ }^{24}$, en la cual la economía queda protegida de la denominada «presión de la calle» y, al mismo tiempo, está subordinada a una política económica reglada y ejecutada por los Bancos centrales y las autoridades de regulación.

El dilema que afronta la teoría de la democracia y del Estado de Derecho es, en resumidas cuentas, radical. En el plano de las relaciones internacionales el efecto principal de la crisis de los antiguos Estados nacionales han sido dos: 1) un vació de derecho público internacional, es decir una falta de reglas, de límites y de vínculos para garantizar la paz, la justicia y los derechos humanos en

\footnotetext{
${ }^{24}$ Crouch, C. (2009), Postdemocrazia. Bari: Laterza.
} 
relación con los nuevos poderes transnacionales, públicos o privados, que han depuesto a los viejos poderes estatales, o se han sustraído a su acción de gobierno y de control; 2) una regresión neo-absolutista y anarco-capitalista por parte de las grandes Estados centrales, como de los grandes poderes económicos mundiales, que se manifiesta política y económicamente bajo el pabellón de la ley del más fuerte: por un lado, en el deterioro de la ONU como garante de la paz, acompañado del renovado recurso a la guerra para solucionar los problemas y las controversias internacionales; por otro lado, en la ausencia de reglas, reivindicada abiertamente por el anarco-capitalismo actual como una especie de grundnorm del nuevo orden económico internacional. La globalización misma de la economía puede ser identificada, en el plano jurídico, con esta ausencia de derecho público internacional adecuado para someter a los grandes poderes económicos transnacionales: no se trata de una ausencia de derecho, sino de un vacío de derecho público colmado, inevitablemente, en su totalidad por el derecho privado que se convierte, inexorablemente, en la ley del más fuerte. Es, por lo tanto, la falta de una esfera pública internacional capacitada para enfrentarse a los nuevos poderes súper-estatales, el auténtico, colosal problema derivado de la crisis del Estado de Derecho. Ahora bien, la respuesta a la crisis legal y jurídica que aflige a la democracia, y que está poniendo en juego todas las conquistas políticas de la modernidad, está siendo principalmente filosófica ${ }^{25}$ ya que - ipor fin! - se han impugnado los dos dogmas fundamentales del pensamiento filosófico posmoderno: «que toda la realidad sea socialmente construida e infinitamente manipulable» ${ }^{26}$, y «que la verdad sea una noción inútil porque la solidaridad es más importante que la objetividad». ${ }^{27}$ En efecto, y coherentemente con sus presupuestos epistemológicos y ontológicos -en el Posmodernismo maquiavélico encontramos el antirrealismo metafísico, la subjetividad epistemológica, el posicionamiento de los sentimientos en la raíz de todas las cuestiones de valores, el consecuente relativismo, tanto del conocimiento cuanto de los valores, y la consiguiente desvaluación o desprecio del emprendimiento científico -, el postulado posmoderno del «no hay hechos, sólo interpretaciones» ha desenmascarado finalmente su auténtico significado: «la razón del más fuerte siempre es la mejor». ${ }^{28} \mathrm{Ha}$ llegado el momento de pasar página definitivamente, si queremos poner remedio al daño procurado por la

\footnotetext{
${ }^{25}$ Ferraris, M. (2012), Manifesto del nuovo realismo. Bari: Laterza.

${ }^{26}$ Berger, Peter L.; Luckmann, Thomas (1986), La construcción social de la realidad. Buenos Aires: Amorrortu.

${ }^{27}$ Rorty, R. (1996), Contingencia, ironía y solidaridad, Barcelona: Paidós.

28 Hicks, S. (2014), Explicando el Posmodernismo, la crisis del socialismo, Buenos Aires: Barbarroja.
} 
regresión neo-absolutista y anarco-capitalista de las grandes Estados centrales y de los grandes poderes económicos mundiales.

\section{Posverdad, marketing político y tecnocracia}

El problema central es que la democracia representativa ha perdido parte de su escaso poder también con respecto a la gestión de los procedimientos electorales clásicos. El segundo mandato de gobierno de Barack Obama ha sido definido como la victoria de los Big Data, puesto que parece imprescindible para la política de hoy en día afirmarse online antes que offline. Y, en efecto, también en la campaña electoral de Donald Trump, que consideraba a la mayor parte de los grandes medios de comunicación como hostiles y prejuiciados en su contra (ya que la gran mayoría de la prensa escrita y las cadenas de televisión estadounidenses apoyaron a la candidata demócrata, Hillary Clinton), Facebook y Twitter fueron determinantes para hacer llegar su mensaje directamente a los votantes sin tener que pasar por el escrutinio de ningún periodista inoportuno. ¿Habría llegado Trump a la presidencia de los Estados Unidos si no hubieran existido Facebook y Twitter? Es algo difícil de saber, pero lo que sí parece claro es que las redes sociales sirvieron para polarizar los puntos de vista de los votantes en una campaña que ya era dura, y pueden haber animado a algunos electores indecisos a salir en apoyo de Trump. Está claro, además, que hemos llegado al punto de considerar la democracia como atributo de la Red, ya que se le asigna el valor taumatúrgico de transformar el flujo de nuestras conversaciones online en predicciones políticas, con independencia de si los objetos de dichas conversaciones giren en torno a la verdad política, ya que durante las campañas electorales las fábricas de fake news se multiplican cada vez más. Y es que el dogma sofista de la posverdad - «no hay hechos, sólo interpretaciones» - comulga a la perfección con las fábricas de mentiras políticas, se hallen donde se hallen, y sean del signo político que sean.

Ahora bien, ante la insignificancia de la hermenéutica posmodernista y nihilista, los hechos objetivos no se pueden enmendar; es decir, la realidad no se puede reducir al conflicto infinito de opiniones y de voluntades de potencias. De hecho las desigualdades económico-sociales que sufren los pueblos por causa de la crisis sistémica que aflige a la democracia representativa, las vidas (y las muertes) de las personas que piden a gritos que sus necesidades reales y sus derechos sean respetados - y que por eso no aguantan un minuto más verse reducidas a meras interpretaciones - están reafirmando el principio de la realidad, la idea de que los hechos objetivos existen (al igual que siguen siendo 
irrefutables tanto el principio de identidad $\mathrm{A}=\mathrm{A}$, como el principio de nocontradicción, ya que «es imposible creer que Madrid está en España y creer a la vez que Madrid no está en España»), independientemente de nuestros sentimientos, de nuestra voluntad, de nuestras estructuras mentales y del construccionismo social, y que el neo-realismo filosófico tiene implicaciones no sólo ontológicas y epistemológicas, sino también éticas y políticas. Es más, la ética contemporánea constituye precisamente el ámbito de investigación que ha logrado desmentir más directa y contundentemente la tesis del fin de la filosofía, gracias a sus perspectivas neorrealistas, naturalistas, neo-intuicionistas, fenomenológicas y normativas. En este sentido, se puede afirmar que el ataque de la contra-Ilustración a la razón teórica ha fracasado, ya que finalmente la razón práctica ha sabido salir al encuentro con sus razones específicas, con su ley constitutiva de la casualidad. El problema es que, volviendo a la cuestión práctica de las campañas electorales en la época de la Computación en Nube, las redes sociales como Facebook y Twetter, con su digital profiling, filtran la información que envían a la Ciudadanía 2.0 de tal modo que esta acaba expuesta sólo a las interpretaciones de la realidad, a las ideas y posverdades que le son afines, desechando argumentos contrarios y enriquecedores. La democracia real requiere que los ciudadanos dialoguemos, discutamos y veamos las cosas desde otros puntos de vista, pero en lugar de eso estamos cada vez más encerrados en nuestras burbujas de filtros. ¿Qué percepción de la realidad tendríamos si sólo viésemos contenidos de una fuente o de una determinada corriente de pensamiento? Por ejemplo, ¿si sólo leyésemos contenidos de La Razón? ¿O si sólo pudiésemos leer información de El País? ¿Y qué pasaría si sólo pudiésemos ver las sombras proyectadas por el fuego sobre la pared de la Caverna de Platón? Ciertamente nuestra realidad estaría influenciada por eso que vemos y leemos, ya que no tenemos forma de contrastar lo que ven y dicen otros.

Pues bien, en las redes sociales y en los demás servicios privados de Internet ocurre algo similar: nos muestran lo que creen que queremos ver, no la realidad ni lo que necesitamos ver. Y lo que es más peligroso: nosotros no tenemos el control ni el poder para salir de nuestras burbujas de filtros. Somos prisioneros de las cavernas, ya que toda la información que nos llega depende de la voluntad arbitraria de los dueños digitales de la Computación en Nube que nos impone su marketing político. Según Pariser, en efecto, la burbuja de filtros - o echo chambers - es una selección personalizada de la información que recibe cada individuo que le introduce en una burbuja adaptada a él para que se encuentre cómodo, pero que está aislada de las de los demás. ${ }^{29}$ Lo que haya en la burbuja

\footnotetext{
${ }^{29}$ Pariser, Eli (2011), The Filter Bubble: What the Internet Is Hiding from You, Nueva York: Penguin
} 
de filtros, en efecto, depende de cada cual, de lo que cada uno haga y de donde cada uno viva. El aspecto positivo de la personalización de la información afirman sus partidarios - es que muestra la visión de un mundo hecho a medida que se ajusta a nosotros a la perfección: una situación en la que la información, ideas o creencias son amplificadas por transmisión y repetición en un sistema «cerrado» de mónadas de Leibniz. Sin embargo, precisamente este aspecto de la personalización de la información donde las visiones diferentes o competidoras son censuradas o prohibidas nos impide conocer otras ideas, otras formas de pensar, que pueden enriquecer nuestro conocimiento del mundo e incluso estimular nuestra creatividad, al poder acceder a disciplinas que en principio nos son ajenas.

Desde el punto de vista de la razón práctica, además, el problema de la burbujas de filtros radica en que los algoritmos que filtran y personalizan la información en la Computación en Nube todavía no tienen incorporados los principios éticos que tienen los editores de los periódicos y de los libros, así como no tienen incorporados responsabilidades cívicas y políticas, ni están diseñados para ofrecer a los ciudadanos de la Red un buen flujo de información contrastada, y menos aún de conocimiento científico. Asimismo, la personalización de la información no es un regalo desinteresado que recibimos; los gigantes de internet ganan su dinero a través de la publicidad y, por lo tanto, hay un acuerdo con los usuarios: tú obtienes este producto que cuesta miles de millones de dólares poner en marcha, y en cambio, nosotros vendemos tus perfiles digitales a los anunciantes para que te envíen publicidad a medida. Es decir, a cambio del servicio de filtrado, de nuestra cómoda burbuja, cedemos a las grandes empresas un ingente volumen de datos relativos a nuestra vida cotidiana. Curiosamente, gran parte de la misma no se la confiaríamos ni a nuestros mejores amigos. El punto es que estos datos son un verdadero tesoro en los tiempos del micro-targeting, que es aquella técnica que se encuentra a medio camino entre el marketing digital y las nieblas de la persuasión oculta: si yo sé lo que te gusta, lo que odias, lo que te une a otras personas, cuánto influye tu juicio sobre ellas y cuánto te afectan algunos temas, estoy en las condiciones de ofrecerte contenidos ad hoc dándote la sensación de que eres tú el que los eliges. Mientras que es verdadero exactamente lo contrario. Y ya es un hecho que estas empresas digitales explotan cada vez más y mejor nuestros datos para hacer no solamente marketing publicitario sino también marketing político, como quedó patente en el escándalo «Data-Gate» - descubierto por The New York Times y The Observer - concerniente la empresa Cambridge Analytica que

Press. 
adquirió gracias a Facebook los datos perfilados de 50 millones de usuarios estadunidenses de la red social, influyendo decisivamente en las elecciones presidenciales estadounidenses.

Para colmo de males, la Computación en Nube es invocada como garante de la horizontalidad de la democracia a pesar de estar en las manos de las empresas y no de los Estados. Es por eso que, evidentemente, los Estados tienden cada vez más a unirse en mega-Estados que colaboran con las conglomeradas hi-tech: al final no existen francotiradores. El modelo tecno-político sino-americano tiene en común la presión cada vez más importante hacia la trasparencia digital más radical y, más en concreto, China está creando el prototipo de un Estado de policía hi-tech. Los próximos pasos posiblemente serán: dotar a cada ciudadano chino de una cuenta de correo electrónico, de un perfil para las redes sociales gobernativas, de una cuenta para consumir en los sitios web autorizados y de un espacio web para compartir los propios datos en los servidores del régimen. Una especie de Facebook chino nacionalizado con una cuenta Gmail integrada y china, que almacena los datos en las Nubes chinas, con el objeto - gracias al digital profiling - de sugerir las próximas compras en Aliexpress, el análogo chino de Amazon.

Un escenario parecido evidencia que las políticas de los gigantes de las TIC, sobre todo de aquellos que necesitan de un profiling cada vez más detallado para aumentar sus ganancias, son perfectamente compatibles con sistemas de control autoritarios y, además, son tecnologías deseables para las dictaduras modernas. Ahora bien, lo que propicia la constitucionalización de este paradigma tecnopolítico es precisamente la complacencia y la adhesión de los usuarios al profiling y a la trasparencia, de manera que el capitalismo autoritario chino no es incompatible con el capitalismo democrático estadounidense, ya que el horizonte común es el del crecimiento económico ilimitado. El punto es que ese modelo tecno-político puede existir gracias a la colaboración global entre diversas élites democráticas, autocráticas y despóticas e implica fenómenos de explotación estructural y de expropiación cognitiva, emotiva y económica de los usuarios en todo el mundo, pero también de la mano de obra a bajo costo y de los recursos primarios sobre todo en Asia y en África. Es decir, esta Red anarco-capitalista ${ }^{30}$ crea una especie de cortocircuito antidemocrático, una especie de estado de excepción de masas, para glosar la expresión de Agamben ${ }^{31}$. Desde un punto de vista antropológico, además, la Computación en Nube es un «no-lugar» ${ }^{32}$ en el

\footnotetext{
${ }^{30}$ Ippolita (2013), Nell'acquario di Facebook. La resistibile ascesa dell'anarco-captalismo. Bari: Laterza.

${ }^{31}$ Agamben, G. (2008), Stato di eccezione, Torino: Bollati Boringhieri.

${ }^{32}$ Augé, M. (2005), Los no lugares: espacio del anonimato. Una antropología de la sobremoderniad.
} 
cual los derechos civiles prácticamente se evaporan: en efecto, para reunirse en las asambleas, en sus ágoras digitales, los ciudadanos tienen que recorrer un largo camino en las redes electrónicas y todos sus pasos son grabados y cuidosamente catalogados en una serie de check point públicos o privados. Una vez alcanzado el ingreso de la plataforma digital deseada, y para acceder finalmente al espacio sagrado donde ejercer su derecho de ciudadanía activa, los ciudadanos deben pedir el permiso a los agentes dominantes de la Computación en Nube para entrar y hacerse identificar, concediendo toda una serie de pruebas a través de los procedimientos de control del login para demostrar su verdadera identidad. Y paradójicamente (¿o no?) lo que ocurre es que cuanto más visibles y trasparentes se hacen los ciudadanos de la Red en las redes sociales gracias al digital profiling, más invisible, secreto y autocrático será el poder político de los dueños de la Red.

En efecto, la democracia es el intento de que el poder sea visible para todos. Es, o debería ser, poder público o del pueblo, aquella forma de gobierno en la que la esfera del poder invisible se hace mínimo. ¿Cómo podrían ser elegidas personas que no se dejan ver? En la actualidad, sin embargo, el poder político tiende a ocultarse; es tanto más poderoso cuanto menos se deja ver. La autocracia, en efecto, no puede prescindir del «gabinete secreto», el lugar en el que precisamente el poder es tan poco visible como pueda llegar a serlo. Las decisiones deben tomarse en secreto porque el pueblo no debe conocer, no debe saber. Ya advertía Arendt a propósito del totalitarismo: «La única regla de la que todo el mundo puede estar seguro en un Estado totalitario es que, cuanto más visibles son los organismos de Gobierno, menor es su poder, y que cuanto menos se conoce una institución, más poderosa resultará ser finalmente. De acuerdo con esta norma, los soviets, reconocidos por una Constitución escrita como la más alta autoridad del Estado, tienen menos poder que el Partido Bolchevique; el Partido Bolchevique, que recluta abiertamente a sus afiliados y es reconocido como la clase dominante, tiene menos poder que la policía secreta; el poder auténtico comienza donde empieza el secreto». ${ }^{33}$

\section{Conclusiones: la necesaria reglamentación de la sociedad digital}

La mayoría de los agentes dominantes, incluyendo a los dueños de la Computación en Nube, se reconoce abiertamente en el anarco-capitalismo y

Barcelona: Gedisa.

${ }^{33}$ Arendt, H. (1987), Los orígenes del totalitarismo, Madrid: Alianza, pág. 608. 
promueven el uso de las tecnologías buenas «por naturaleza», libres y democráticas. Sin embargo, el anarco-capitalismo sufre de las mismas contradicciones insanables de cada teoría política deontológica y monista, al considerar la «libertad negativa» como el único valor ético y político a tomar en cuenta por estar inscrito, presumiblemente, en el código genético humano. En cuanto código (y derecho) natural, por lo tanto, la libertad negativa se puede extraer, computar y alimentar a los algoritmos. De esta manera las computadoras y las máquinas digitales garantizarían la libertad negativa automática, y el objeto de la sociedad consistiría únicamente en la implementación, gracias a la contribución de todos, de tecnologías cada vez mejores. El imperio de los Big Data se reduce así a una especie de «algocracia» en la cual la libertad del individuo es realizable sin ningún esfuerzo: las masas deben solamente hacerse radicalmente trasparentes a las tecnologías, compartir cada cosa, para llegar a ser auto-mágicamente libres. Frente a los dueños digitales, los Estados centrales o los dueños analógicos, utilizan sus agencias de seguridad, vigilancia y espionaje nacionales para fomentar la lucha contra el terrorismo internacional, la seguridad nacional y la defensa de los valores liberales. Los Estados centrales, de hecho, controlan de manera incesante e indiscriminada (y por eso injusta) a todos los ciudadanos de la Red, a pesar de que quienes vigilan realmente las masas digitales son, en realidad, los agentes dominantes de la Computación en Nube que extraen valor de la biodiversidad humana. Diferentes en los objetos (comerciales para algunos y políticos para otros) pero iguales, digitales y analógicos se encuentran y colaboran en cuanto coinciden en ser dueños de algo. Resulta por lo tanto evidente que el digital profiling constituye la práctica fundadora del mito posmoderno de la Red libre y democrática. En la era de la Revolución informática, la técnica del profiling se ha extendido a toda la población digitalizada con el objeto de identificar segmentos de mercado cada vez más específicos (publicidad justa para el usuario justo), y para efectuar data mining (Sentiment analysis, Opinion mining, Nowcasting), es decir, para extraer información oculta y predecible de los Big Data. En sentido político, la Ciudadanía 2.0 se identifica especificadamente con la capacidad de profiling libre y espontaneo de los ciudadanos de la Red que estipulan una delegación o mandato de gobierno privado con los dueños de la Computación en Nube (a su vez relacionados con los Estados centrales) para la defensa de sus derechos privados. O sea, en la época de la posdemocracia, y en nombre de la nueva libertad negativa automática y gratuita, los ciudadanos de la Red con sus plataformas de e-democracy parecen haber optado, tal vez inconscientemente, por una rendición incondicional a la tecnocracia y al anarco-capitalismo de 
los right libertarians californianos, en lugar de reivindicar una mayor espacio público para ejercer su razón práctica y defender también la libertad republicana.

Ahora bien, la deliberación política, es decir aquella forma de gobernar en la cual ciudadanos libres e iguales se incorporan a un proceso de intercambio de razones y argumentos que se realiza de forma pública y comprensible, y que sirve para justificar unas decisiones concretas, posee un alto grado de dificultad. En efecto, los asuntos de las agendas parlamentarias son tan complejos que no pueden plantearse esquemáticamente en los instrumentos de participación política como la consulta popular. Problemas como el equilibrio entre el crecimiento económico que requiere de la explotación de recursos naturales y los compromisos mundiales ecológicos, las políticas del uso de energías y los riesgos tecnológicos o ambientales, o la explosión demográfica y la migración vinculadas al desempleo; son cuestiones tan sofisticadas que, de acuerdo con Macpherson, los ciudadanos no pueden generar "las respuestas [que] constituyeran una directriz clara dada al gobierno". ${ }^{34}$ Por lo tanto, no es viable una democracia donde los ciudadanos indiquen a sus representantes los imperativos bajo los cuales actuarán en nombre de ellos, ni siquiera por ellos o a cuenta de ellos. Consecuentemente, no podemos prescindir de los políticos elegidos, quienes deben dominar la agenda pública y el procedimiento de toma de decisiones.

En contraste con el dogmatismo posmoderno, los ciudadanos de la Red necesitamos una Computación en Nube diferente, que nos provea no sólo los medios digitales para que podamos conseguir información y conocimiento veraz sobre los asuntos públicos que nos interesan a todos, - evitando la manipulación ideológica de la realidad, el marketing político y las fakes news -, sino que también nos independice de las cadenas de burbujas de filtros para que consigamos finalmente intercambiar razones y escuchar opiniones diferentes con el fin de tomar las mejores decisiones en el ámbito de las políticas públicas. Queremos salir de la fábula posmoderna de la Red libre y democrática y no depender más de la voluntad arbitraria de los dueños digitales y de los dueños analógicos de la Red que representan, en su conjunto, la posmoderna «razón del más fuerte». Como hemos dicho anteriormente, la verdadera libertad republicana se concibe no solamente como independencia de la voluntad arbitraria de otros individuos, sino sobre todo como dependencia de la ley. Es por eso que necesitamos poner en marcha una reglamentación jurídica de la sociedad digital para que nuestros datos personales sean protegidos de verdad y para que nadie tenga el poder absoluto de hacer con ellos todo lo que quisiera a nivel

\footnotetext{
${ }^{34}$ Macpherson, C. B. (1982), La democracia liberal y su época, Madrid: Alianza Editorial, pág. 116.
} 
planetario $^{35}$. En efecto, ante el panorama de una sociedad tecnológica tan compleja donde casi todo está codificado, procesado y declinado en protocolos interpretables por los algoritmos, ¿qué queda realmente del hombre político? (La pregunta es pertinente ya que, de acuerdo con los filósofos republicanos de la

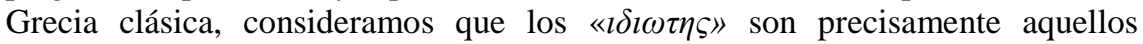
ciudadanos que no se ocupan de los asuntos públicos sino sólo de sus intereses privados). O mejor dicho: ante las acciones y los comportamientos humanos instantáneamente procesados, anticipados y condicionados por los algoritmos, ¿qué espacio queda para la libertad republicana del hombre?

Según nuestra opinión, la nueva frontera de la «computación cognitiva» ${ }^{36}-$ en la que los ordenadores no se programan sino que son capaces de entender el lenguaje natural de las personas y aprender -, podría brindar quizás la posibilidad, para el ciudadano de la Red, de hacer frente a los asuntos públicos conjugando la habilidades propias del pensamiento computacional, del pensamiento crítico-científico y del pensamiento moral. El valor de la computación cognitiva radica en su propósito de unir la inteligencia artificial de las máquinas con las capacidades racionales y morales del hombre. Como hemos visto, en el ámbito tecnológico lo frecuente es que la persona se adapte a la máquina. Pero con la computación cognitiva no es así, ya que está programada para interactuar con las personas de una manera más natural: lee y entiende el lenguaje natural de las personas, con su riqueza de matices y giros lingüísticos. Se alimenta de datos procedentes de múltiples fuentes: datos estructurados en bases de datos o datos no estructurados; es decir, libros, informes de investigación, tweets, blogs, imágenes. Es capaz de procesar millones de datos en cuestión de segundos y responder a preguntas complejas casi en tiempo real. Ante una pregunta, formula hipótesis y escoge la respuesta en la que tiene un mayor nivel de confianza. Muestra los pasos que ha dado para llegar a esta respuesta de una forma clara y sencilla, es decir, presenta su razonamiento. Y, además, aprende de su experiencia, de cada interacción, así que cada vez es más inteligente. Por eso, sería muy deseable que, en un futuro próximo, la computación cognitiva fuera capaz de ofrecer nuevos servicios y aplicaciones en la Nube aprovechando el conocimiento científico y la información disponible sobre cualquier asunto de interés público. Bajo nuestra perspectiva neo-realista y neo-moderna, en efecto, debemos superar el relativismo posmoderno, tanto del conocimiento cuanto de los valores, y la consiguiente devaluación o desprecio de la ciencia. De manera que algún día, en lugar de consultar gratuitamente a un

\footnotetext{
${ }^{35}$ Bernabè, F. (2012), Libertà vigilata. Privacy, sicurezza e mercato nella rete, Bari: La Terza.

${ }^{36}$ Kai Hwang-Min Chen (2017), Big-Data Analytics for Cloud, IoT and Cognitive Computing. John Wiley \& Sons Ltd.
} 
metabuscador como Google para obtener los resultados más relevantes filtrados por los algoritmos personalizados, podamos - con la ayuda de asistentes cognitivos - plantear una pregunta a la máquina cognitiva, con el fin de que procese la información en función de lo que haya aprendido en su lectura de millones y millones de documentos y sensores, y nos ofreciera finalmente su respuesta o recomendación. La revolución de la computación cognitiva podría promover un cambio radical en la forma en que accedemos a la información y al conocimiento científico, y en la manera de afrontar ética y racionalmente los asuntos públicos y la toma de decisiones democráticas sobre ellos.

Volvemos a repetir, pues, con Bustamante, la idea que expusimos al principio del artículo, es decir que "las tecnologías, igual que las leyes, son formas de vida: regulan la manera de entender el trabajo, el ocio, la participación política, y casi cualquier aspecto de la vida social que podamos imaginar"; de tal manera que si conseguimos cambiar las tecnologías, o los fines para los cuales se implementan las aplicaciones de las máquinas digitales, la gran oportunidad histórica que tendrá la Ciudadanía 3.0 será la de participar en el debate sobre los asuntos públicos que afectan a la libertad y la justicia de la «res publica global» - la pobreza, la biodiversidad, la salud, el calentamiento global, la escasez energética, el terrorismo, las pandemias, la seguridad, la lucha contra el crimen, la bioética, etc. - de manera inteligente, informada y responsable. En efecto, la excelencia política depende de saber generar las ideas más verdaderas sobre el bien común y elegir la política pública correspondiente; a su vez, esas ideas y elecciones dependen de la movilización del conocimiento al ámbito político. En definitiva, se trataría de utilizar las maquinas cognitivas para reunir información y conocimiento para el entendimiento de los complejos asuntos públicos. De esta forma, el ejercicio de nuestra razón práctica y de nuestra libertad republicana, estarían basados finalmente en hechos verificables y sustentados por evidencias recogidos mediante el método científico, así como en la elaboración de nuevos conocimientos y en un sistema jerárquico de valores éticos universales, en lugar de hacerlos depender de nuestros instintos o sentimientos, de nuestras interpretaciones inciertas, de las representaciones ideológicas del mundo, del construccionismo social o, - como ocurre más a menudo hoy en día - de los intereses económicos de los dueños digitales de la Red en comunión con la voluntad política absolutista de los dueños analógicos. 


\section{Referencias bibliográficas}

Agamben, G., Stato di eccezione, Torino, Bollati Boringhieri, 2008.

Aguirre Sala, J.F., La democracia líquida. Los nuevos modelos políticos en la era digital, Barcelona, Editorial UOC, 2017.

Arendt, H., Los orígenes del totalitarismo, Madrid, Alianza, 1987.

Augé, M., Los no lugares: espacio del anonimato. Una antropología de la sobremoderniad. Barcelona, Gedisa 2005.

Berger, Peter L.; Luckmann, Thomas, La construcción social de la realidad. Buenos Aires, Amorrortu, 1986.

Bernabè, F., Libertà vigilata. Privacy, sicurezza e mercato nella rete, Bari, La Terza, 2012.

Bobbio, N., Liberalismo e Democrazia, Milano, Franco Angeli, 1986.

Bobbio, N., El futuro de la democracia, México, Fondo de Cultura Económica, 2005.

Bustamante, J., "Ética en la nube: dilemas éticos y políticos en el modelo de Computación en Nube (Ethics on the cloud: ethical and political dilemmas in the model of Cloud computing)", en Argumentos de Razón Técnica, (2013), n 16, pp. 37-54.

Castoriadis, C., Democracia y Relativismo: debate con el MAUSS (Mouvement Anti-Utilitariste dans les Sciences Sociales), Madrid, Trotta, 2007.

Constant, B., Sobre la libertad de los antiguos en comparación con la de los modernos, Madrid, Tecnos, 2002.

Crouch, C., Postdemocrazia. Bari, Laterza, 2009.

Ferraris, M., Manifesto del nuovo realismo. Bari, Laterza, 2012.

Gómez Adanero, M., Filosofía del Derecho, Madrid, UNED, 2013.

Hicks, S., Explicando el Posmodernismo, la crisis del socialismo, Buenos Aires, Barbarroja, 2014.

Ippolita, Nell'acquario di Facebook. La resistibile ascesa dell'anarcocaptalismo. Bari, Laterza, 2013.

Kai Hwang-Min Chen, Big-Data Analytics for Cloud, IoT and Cognitive Computing. John Wiley \& Sons Ltd., 2017.

Kelsen, H., Teoría pura del derecho, Madrid, Trotta, 2011.

Macpherson, C. B., La democracia liberal y su época, Madrid, Alianza Editorial, 1982.

Michels, R., Political Parties. A Sociological Study of the Oligarchical Tendencies of Modern Democracy, USA: Library of Congress. Transaction Publishers. New Jersey, 1910. 
Pariser, E., The Filter Bubble: What the Internet Is Hiding from You, Nueva York, Penguin Press, 2011.

Queraltó, R., La Estrategia de Ulises o Ética para una Sociedad Tecnológica, Madrid-Sevilla, CICTES-Doss. Ed., 2008.

Queraltó, R. (2000), El caballo de Troya al revés: diseño de una estrategia ética en la sociedad tecnológica, [en De Mora, Ibarra, Pérez Sedeño y Sánchez Balmaseda, coord.: Actas del III Congreso de la Sociedad de Lógica, Metodología y Filosofía de la Ciencia en España, San Sebastián, Universidad del País Vasco] págs. 301-308.

Rorty, R., Contingencia, ironía y solidaridad, Barcelona, Paidós, 1996.

Rousseau, J., El contrato social, en Escritos de combate, Madrid, Alfaguara, 1979.

Salamone, M.A., "La idea del contrato social en M. Salamone de Alberteschi. Sus vínculos con la Escuela de Salamanca y el Constitucionalismo inglés", Madrid, Universidad Complutense, 2006. "La doctrina política del contractualismo en M. Salamone y la Escuela de Salamanca" en Ciencia $e$ investigación en la sociedad actual, Salamanca, Editorial San Esteban, 2010; "De las primeras Cartas de derechos a la Declaración Universal de los Derechos Humanos" en Los derechos humanos en su origen. La República dominicana y Antón Montesinos, Salamanca, Editorial San Esteban, 2011.

Sen, A., La idea de la justicia, Madrid, Taurus, 2010.

VESTRI, Gabriele. ¿La democracia líquida como alternativa a la política clásica? Un estudio contextual. Estudios de Deusto, [S.1.], v. 63, n. 1, p. 403-422, jul. 2015. ISSN 2386-9062. Disponible en: <http://revistaestudios.revistas.deusto.es/article/view/188/310>. Fecha de acceso: 02 dic. 2018 doi:http://dx.doi.org/10.18543/ed-63(1)-2015pp403-422.

Viroli, M., Dalla política alla ragion di Stato, Milano, Donzelli, 1994.

Winner, L., La ballena y el reactor, Barcelona, Gedisa, 2008. 